\title{
Delivery of recombinant SARS-CoV-2 envelope protein into human cells
}

James M. Hutchison ${ }^{\mathrm{a}, \mathrm{b}, 1}$, Ricardo Capone $\mathrm{e}^{\mathrm{b}, \mathrm{c}, 1}$, Dustin D. Luu ${ }^{\mathrm{d}, \mathrm{e}}$, Arina Hadziselimovic ${ }^{\mathrm{b}, \mathrm{c}}$, Wade D. Van Horn ${ }^{\mathrm{d}, \mathrm{e}, 2 *}$, and Charles R. Sanders ${ }^{\mathrm{b}, \mathrm{c}, \mathrm{f}, 2}$

a Chemical and Physical Biology Graduate Program, Vanderbilt University, Nashville, TN, 37240 USA

${ }^{b}$ Center for Structural Biology, Vanderbilt University, Nashville, TN, 37240 USA

${ }^{c}$ Department of Biochemistry, Vanderbilt University, Nashville, TN, 37240 USA

dSchool of Molecular Sciences, Arizona State University, Tempe, AZ 85287 USA

e The Biodesign Institute Centers for Personalized Diagnostics and Mechanisms of Evolution, Arizona State University, Tempe, AZ 85281 USA

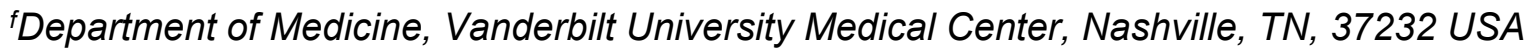

${ }^{1}$ These authors contributed equally.

2For correspondence: wade.van.horn@asu.edu or chuck.sanders@vanderbilt.edu

ORCID: JMH: 0000-0002-5529-3248 RC: 0000-0002-7327-9837 DDL: 0000-0003-3464-160X WDVH: 0000-0002-2493-5578 CRS: 0000-0003-2046-2862

Running Title: Delivery of the SARS-CoV-2 E protein to cells.

Keywords: COVID, SARS, CoV-2, coronavirus, envelope, E protein, amphipol, ion channel, planar bilayer, membrane, insertion, ERGIC, Golgi. 


\begin{abstract}
SARS-CoV-2 envelope protein (S2-E) is a conserved membrane protein that is essential to coronavirus assembly and budding. Here, we describe the recombinant expression and purification of S2-E into amphipol-class amphipathic polymer solutions. The physical properties of amphipols underpin their ability to solubilize and stabilize membrane proteins without disrupting membranes. Amphipol delivery of S2-E to pre-formed planar bilayers results in spontaneous membrane integration and formation of viroporin ion channels. Amphipol delivery of the S2-E protein to human cells results in membrane integration followed by retrograde trafficking to a location adjacent to the endoplasmic reticulum-to-Golgi intermediate compartment (ERGIC) and the Golgi, which are the sites of coronavirus replication. Delivery of S2-E to cells enables both chemical biological approaches for future studies of SARSCoV-2 pathogenesis and development of "Trojan Horse" anti-viral therapies. This work also establishes a paradigm for amphipol-mediated delivery of membrane proteins to cells.
\end{abstract}

\section{Introduction}

The severe acute respiratory syndrome 2 virus (SARS-CoV-2) became a focal point of science and society in 2020 . It is to be hoped that the ongoing vaccine development and delivery program will soon allow the world to return to an approximation of normalcy $(1,2)$. However, previous coronavirus (CoV) epidemics, including Middle East respiratory syndrome (MERS) (3) and SARS (4) from 2002-2003 foretell that future CoV zoonotic events (5) are likely to afflict humankind. Fundamental studies of the molecular underpinnings of CoVs may help to mitigate the current and future pandemics.

Within CoVs, there are four critically conserved structural proteins $(6,7)$, each of which is of possible therapeutic importance due to their essential functions (8), Among these is the SARS-CoV-2 envelope (E) protein. The $\mathrm{E}$ protein is a single-pass transmembrane protein whose roles in pathogenesis are incompletely understood (9). However, its importance is highlighted by cellular studies showing that the CoV E and $M$ proteins alone are sufficient to produce a budding virus-like particle (VLP) (10-12). Moreover, deletion of $\mathrm{E}$ drastically lowers viral fitness (13-15) and growing evidence suggests that $E$ is directly responsible for acute respiratory distress syndrome (ARDS) occurring in conjunction with $\mathrm{CoV}$ infections (16). E is highly expressed in infected cells, but only a small fraction is incorporated into mature viral particles, implying functions beyond its role as a mature capsid structural protein (17). Supporting this idea, the $E$ protein is known to populate both monomer and oligomer forms in vivo (18). Most biophysical measurements have focused on the homopentamer form that functions as a cation-selective ion channel (19-22), which is analogous to a well-studied and validated drug target, the influenza M2 protein $(23,24)$.

A distinct feature of coronavirus assembly is that their nascent particles bud into the lumen of the endoplasmic reticulumto-Golgi intermediate compartments (ERGIC) in cells (25). The $E$ protein is critical to viral maturation $(10,17,26)$. Localization of SARS $E$ to these membranes is remarkably stringent, likely a consequence of Golgitargeting motifs present in the E protein (26). Since $E$ functions in multiple roles that are critical to viral fitness (27-29), it is desirable to develop methods to further characterize key pathogenic mechanisms. Current methods to study the $E$ protein in mammalian cells are reliant on transfection of genetic material encoding the protein into cells and its subsequent transcription and/or 
translation. Here, we sought to develop a robust method for exogenous delivery of purified SARS-CoV-2 envelope protein (S2E) into cells to enable chemical biological methods for studies of S2-E function and to facilitate novel COVID therapies.

\section{Results and Discussion}

We developed a straightforward bacterial expression and purification protocol that yields $\sim 100 \mu \mathrm{g} / \mathrm{L}$ of $90-95 \%$ pure fulllength S2-E under conditions in which it is bereft of detergent and lipid, with its aqueous solubility being maintained by complexation with the zwitterionic amphipol PMAL-C8 $(30,31)$ (Fig. S1 and Supporting Material and Methods). This purification protocol has been streamlined to a single gravity column and does not require a FPLC or ultracentrifuge. Once purified into lipid/detergent-free amphipol solution, the S2-E/amphipol complexes remain stable and soluble in aqueous solution even following removal of excess uncomplexed amphipols. Amphipols are a class of amphipathic polymers that exhibit weak detergent properties, in that they can solubilize and stabilize the native membrane protein folds, but cannot solubilize or even permeabilize membranes $(32,33)$. Additionally, some amphipols are well tolerated by animals (34) and have been used in Chlamydia vaccine development $(35,36)$ because they do not elicit the production of anti-amphipol antibodies (37).

Planar lipid bilayer electrophysiology was used to test if amphipols could deliver the S2-E protein to a membrane environment to form ion channels without otherwise disrupting the lipid bilayer (Fig. 1A). As expected, amphipol-based S2-E delivery resulted in ion channel activity that is consistent with previous SARS-CoV-1 E (38) and preliminary S2-E (39) channel measurements in terms of current amplitudes, sodium cation selectivity, and open probabilities. (Figs. 1B,C, and S2, and Supporting Materials and Methods). The S2E-dependent currents and similarity to other planar bilayer measurements support that the idea that S2-E is released spontaneously from the amphipol into membranes. The bilayer integrity during amphipol delivery and exposure was monitored through membrane capacitance measurements. The bilayers remained stable throughout the recordings with an average value of $58 \pm 3 \mathrm{pF}$. These results demonstrate that recombinant S2-E can be delivered into pre-formed lipid bilayers using amphipols, where the protein not only inserts into the bilayers, but also retains ion channel function, without significantly compromising the bilayer integrity.

We next tested whether S2-E can be delivered from amphipol complexes to the membranes of human cells. To this end, S2$\mathrm{E}$ was irreversibly tagged with the fluorophore nitrobenzoxadiazole (NBD) to form S2-E-NBD. This allowed us to track the time course of delivery of S2-E into HeLa cells using confocal microscopy. As shown in Figs. 2 and S5, the S2-E-NBD protein was delivered from amphipol complexes to HeLa cell membranes, with all cells exhibiting NBD signal within $30 \mathrm{~min}$ (Fig. 2B). Fig. 2C-F shows the 8 hour progression of the S2-ENBD protein from the plasma membranes to a predominately perinuclear intracellular location. After 16-18 h nearly all the S2-E was observed in the vicinity of the nucleus, with a clear focal area on one side of the nuclear compartment rather than being evenly distributed, ring-like, around the entire nucleus (Fig. 2G,H). Delivered S2-E was typically more diffuse at early time points but becomes punctate as it traffics to the perinuclear space.

The amount of S2-E signal in cells was dependent on the applied amphipol/S2$E$ "dose" and no obvious cell toxicity was observed until a concentration of $10 \mu \mathrm{M}$ S2$E$ in the culture was reached (Figs. S3 and S4). To ensure that we were microscopically tracking intact S2-E instead of dye freed from full length S2-E by degradation, we confirmed the S2-E localization following cell fixation and permeabilization with a polyclonal anti-S2-E antibody (Fig. S3). The same Fig. \$3 Western blot data also rules out the possibility that the tracked NBD fluorescence could arise from a minor 
impurity in our S2-E-NBD samples. While amphipols have previously been reported to deliver select membrane proteins to artificial lipid bilayers $(30,40)$, this study represents the first use of amphipols to deliver a protein to live mammalian cells. Elucidation of the pathway(s) taken by the S2-E protein to dissociate from its soluble amphipol complex to then insert into the membrane to adopt a transbilayer configuration will require further study.

We also examined possible delivery of S2-E from amphipol solutions into SW1573 human alveolar cells, a COVID-19relevant cell line (41). We observed (Fig. S4) that S2-E is indeed taken up by these cells and subject to the same cell surface-toperinuclear "retrograde" trafficking as seen in HeLa cells.

During viral replication, most $\mathrm{E}$ protein is retained at the Golgi/ERGIC regions. S2-E retention is important to virion assembly because CoVs assemble and bud from the Golgi/ERGIC space before being secreted. The fact that $S 2-E$ retrograde traffics proximal to one side the nucleus (Fig. $\mathbf{2 G}, \boldsymbol{H})$ is consistent with its localization at or near the Golgi/ERGIC compartments. To gain further insight into the final cellular location of S2-E we used organelle-specific monoclonal antibodies to pinpoint the locations of the Golgi and ERGIC relative to delivered S2-E. At later timepoints after initial delivery, S2-E was typically seen to concentrate in the area surrounding the Golgi, but not within the Golgi, (Figs. 3A-C and S6). In like manner, S2-E was seen to locate proximal to the cytosol-facing side of the ERGIC (see Fig. 3D-F).

It is likely that the Golgi-localization motifs (26) in S2-E drive its retrograde trafficking in a way closely related to the mechanism that facilitates $E$ protein Golgi/ERGIC retention during viral infection. However, we cannot rule out the possibility that the retrograde trafficking documented in Fig. 3 reflects the outcome of a cellular stress response to amphipol-delivered S2-E. Isolated coronavirus $E$ overexpression in transiently transfected model mammalian cell lines is known to induce apoptosis
$(42,43)$. However, comparative studies of cell infection with SARS versus SARS lacking the $E$ gene have shown that lower levels of $E$ protein can modulate the unfolded protein response (UPR) and thereby mitigate apoptosis (44). It is plausible that the amphipol-mediated extracellular delivery of S2-E triggers cell stress and UPR-related retrograde trafficking, leading to deposition of S2-E in perinuclear aggresomes. Aggresomes are ordered protein aggregates that form following transport of certain proteins along microtubes by dynein to perinuclear microtubule-organizing centers (45). Interestingly, previous reports have linked aggresome formation and their subsequent clearance via autophagy to coronavirus replication (46-48). Further study is clearly required. For now, we can confidently state that delivered S2-E ultimately traffics back to a perinuclear area that is immediate to the Golgi and ERGIC compartments which mirrors the localization of SARS-CoV-2 infected cells.

\section{Conclusions}

We have shown that the S2-E protein can be stripped of lipid and detergent and purified into aqueous solutions in which its solubility is maintained solely by complexation with amphipols. The protein can then be delivered to lipid bilayers, in which the protein spontaneously inserts into the membrane to form ion channels. Likewise, addition of the S2-E protein to living human cells results in plasma membrane integration and subsequent retrograde trafficking deep within the cell to a location immediately adjacent to both Golgi and ERGIC compartments, which are believed to be the key locales of coronavirus replication and assembly. The S2-E proteinto-cells approach established by this work should be exploitable as a route to delivering chemically modified full length S2-E to cells in culture or possibly even to cells under physiological conditions. This capability enables a wide range of chemical biological tools to explore the biological function of this protein or to test whether chemical warhead- 
armed S2-E can play the role of a Trojan horse to interfere with SARS-CoV-2 replication, potentially as an anti-COVID therapeutic or prophylactic. The results of this work also establish a general paradigm for using amphipols to deliver membrane proteins to living cells, although whether numerous other membrane proteins can be successfully delivered using this approach remains to be explored.

\section{Data Availability}

All data needed to evaluate the conclusions in the paper and supporting information are presented in the manuscript or in the supporting information. Correspondence and requests for materials should be addressed to WDVH (wade.van.horn@vanderbilt.edu) or CRS (chuck.sanders@vanderbilt.edu).

\section{Acknowledgements}

Special thanks to Abigail C. Neininger for help with fluorescence microscopy.

\section{Author Contributions}

$\mathrm{JMH}, \mathrm{RC}, \mathrm{DDL}$, and $\mathrm{AH}$ conducted all experiments for this work. All authors participated in data analysis and wrote the paper. WDVH and CRS conceived of the work and directed the approaches used.

\section{Funding}

This work was supported by $\mathrm{NIH}$ grants RF1 AG056147 (CRS) and R01 GM112077 (WVH). JMH was supported by NIH T32 CA00958229 and by F31 AG061984. Special thanks to Abigail C. Neininger for help with fluorescent microscopy. The Vanderbilt Cell Imaging Shared Resource is supported by NIH grants CA68485, DK20593, DK58404, DK59637, and EY08126.

\section{Conflict of Interest}

The authors declare no competing financial interest.

\section{Abbreviations}

Severe acute respiratory syndrome 2 virus (SARS-CoV-2), SARS-CoV-2 envelope protein (S2-E), endoplasmic reticulum-toGolgi intermediate compartment (ERGIC), coronavirus (CoV), virus-like particle (VLP), acute respiratory distress syndrome (ARDS), nitrobenzoxadiazole (NBD), unfolded protein response (UPR)

\section{References}

1. Baden, L. R., El Sahly, H. M., Essink, B., Kotloff, K., Frey, S., Novak, R., Diemert, D., Spector, S. A., Rouphael, N., Creech, C. B., McGettigan, J., Kehtan, S., Segall, N., Solis, J., Brosz, A., Fierro, C., Schwartz, H., Neuzil, K., Corey, L., Gilbert, P., Janes, H., Follmann, D., Marovich, M., Mascola, J., Polakowski, L., Ledgerwood, J., Graham, B. S., Bennett, H., Pajon, R., Knightly, C., Leav, B., Deng, W., Zhou, H., Han, S., Ivarsson, M., Miller, J., Zaks, T., and Group, C. S. (2021) Efficacy and Safety of the mRNA-1273 SARS-CoV-2 Vaccine. N. Engl. J. Med. 384, 403-416

2. Polack, F. P., Thomas, S. J., Kitchin, N., Absalon, J., Gurtman, A., Lockhart, S., Perez, J. L., Perez Marc, G., Moreira, E. D., Zerbini, C., Bailey, R., Swanson, K. A., Roychoudhury, S., Koury, K., Li, P., Kalina, W. V., Cooper, D., Frenck, R. W., Jr., Hammitt, L. L., Tureci, O., Nell, H., Schaefer, A., Unal, S., Tresnan, D. B., Mather, S., Dormitzer, P. R., Sahin, U., Jansen, K. U., Gruber, W. C., and Group, C. C. T. (2020) Safety and Efficacy of the BNT162b2 mRNA Covid-19 Vaccine. N. Engl. J. Med. 383, 2603-2615 
3. Zaki, A. M., van Boheemen, S., Bestebroer, T. M., Osterhaus, A. D., and Fouchier, R. A. (2012) Isolation of a novel coronavirus from a man with pneumonia in Saudi Arabia. $N$.

Engl. J. Med. 367, 1814-1820

4. Drosten, C., Gunther, S., Preiser, W., van der Werf, S., Brodt, H. R., Becker, S., Rabenau, H., Panning, M., Kolesnikova, L., Fouchier, R. A., Berger, A., Burguiere, A. M., Cinatl, J., Eickmann, M., Escriou, N., Grywna, K., Kramme, S., Manuguerra, J. C., Muller, S., Rickerts, V., Sturmer, M., Vieth, S., Klenk, H. D., Osterhaus, A. D., Schmitz, H., and Doerr, H. W. (2003) Identification of a novel coronavirus in patients with severe acute respiratory syndrome. N. Engl. J. Med. 348, 1967-1976

5. Mahdy, M. A. A., Younis, W., and Ewaida, Z. (2020) An Overview of SARS-CoV-2 and Animal Infection. Front. Vet. Sci. 7, 596391

6. Satarker, S., and Nampoothiri, M. (2020) Structural Proteins in Severe Acute Respiratory Syndrome Coronavirus-2. Arch. Med. Res. 51, 482-491

7. Kim, D., Lee, J. Y., Yang, J. S., Kim, J. W., Kim, V. N., and Chang, H. (2020) The Architecture of SARS-CoV-2 Transcriptome. Cell 181, 914-921 e910

8. Alam, I., Kamau, A. A., Kulmanov, M., Jaremko, L., Arold, S. T., Pain, A., Gojobori, T., and Duarte, C. M. (2020) Functional Pangenome Analysis Shows Key Features of E Protein Are Preserved in SARS and SARS-CoV-2. Front. Cell Infect. Microbiol. 10, 405

9. Schoeman, D., and Fielding, B. C. (2019) Coronavirus envelope protein: current knowledge. Virol. J. 16, 69

10. Corse, E., and Machamer, C. E. (2000) Infectious bronchitis virus E protein is targeted to the Golgi complex and directs release of virus-like particles. J. Virol. 74, 4319-4326

11. Corse, E., and Machamer, C. E. (2003) The cytoplasmic tails of infectious bronchitis virus $E$ and $M$ proteins mediate their interaction. Virology 312, 25-34

12. Vennema, H., Godeke, G. J., Rossen, J. W., Voorhout, W. F., Horzinek, M. C., Opstelten, D. J., and Rottier, P. J. (1996) Nucleocapsid-independent assembly of coronavirus-like particles by co-expression of viral envelope protein genes. EMBO J.15, 2020-2028

13. Almazan, F., DeDiego, M. L., Sola, I., Zuniga, S., Nieto-Torres, J. L., Marquez-Jurado, S., Andres, G., and Enjuanes, L. (2013) Engineering a replication-competent, propagation-defective Middle East respiratory syndrome coronavirus as a vaccine candidate. mBio 4, e00650-00613

14. Nieto-Torres, J. L., DeDiego, M. L., Verdia-Baguena, C., Jimenez-Guardeno, J. M., Regla-Nava, J. A., Fernandez-Delgado, R., Castano-Rodriguez, C., Alcaraz, A., Torres, J., Aguilella, V. M., and Enjuanes, L. (2014) Severe acute respiratory syndrome coronavirus envelope protein ion channel activity promotes virus fitness and pathogenesis. PLoS Pathog. 10, e1004077

15. DeDiego, M. L., Alvarez, E., Almazan, F., Rejas, M. T., Lamirande, E., Roberts, A., Shieh, W. J., Zaki, S. R., Subbarao, K., and Enjuanes, L. (2007) A severe acute respiratory syndrome coronavirus that lacks the $\mathrm{E}$ gene is attenuated in vitro and in vivo. J. Virol. 81, 1701-1713

16. Schoeman, D., and Fielding, B. C. (2020) Is There a Link Between the Pathogenic Human Coronavirus Envelope Protein and Immunopathology? A Review of the Literature. Front. Microbiol. 11, 2086

17. Venkatagopalan, P., Daskalova, S. M., Lopez, L. A., Dolezal, K. A., and Hogue, B. G. (2015) Coronavirus envelope (E) protein remains at the site of assembly. Virology 478, 75-85

18. Westerbeck, J. W., and Machamer, C. E. (2015) A Coronavirus E Protein Is Present in Two Distinct Pools with Different Effects on Assembly and the Secretory Pathway. J. Virol. 89, 9313-9323 
19. Mandala, V. S., McKay, M. J., Shcherbakov, A. A., Dregni, A. J., Kolocouris, A., and Hong, M. (2020) Structure and drug binding of the SARS-CoV-2 envelope protein transmembrane domain in lipid bilayers. Nat. Struct. Mol. Biol. 27, 1202-1208

20. Parthasarathy, K., Ng, L., Lin, X., Liu, D. X., Pervushin, K., Gong, X., and Torres, J. (2008) Structural flexibility of the pentameric SARS coronavirus envelope protein ion channel. Biophys. J. 95, L39-41

21. Pervushin, K., Tan, E., Parthasarathy, K., Lin, X., Jiang, F. L., Yu, D., Vararattanavech, A., Soong, T. W., Liu, D. X., and Torres, J. (2009) Structure and inhibition of the SARS coronavirus envelope protein ion channel. PLoS Pathog. 5, e1000511

22. Torres, J., Parthasarathy, K., Lin, X., Saravanan, R., Kukol, A., and Liu, D. X. (2006) Model of a putative pore: the pentameric alpha-helical bundle of SARS coronavirus $E$ protein in lipid bilayers. Biophys. J. 91, 938-947

23. Cady, S. D., Luo, W., Hu, F., and Hong, M. (2009) Structure and function of the influenza A M2 proton channel. Biochemistry 48, 7356-7364

24. Pielak, R. M., and Chou, J. J. (2011) Influenza M2 proton channels. Biochim. Biophys. Acta 1808, 522-529

25. Klumperman, J., Locker, J. K., Meijer, A., Horzinek, M. C., Geuze, H. J., and Rottier, P. J. (1994) Coronavirus M proteins accumulate in the Golgi complex beyond the site of virion budding. J. Virol. 68, 6523-6534

26. Cohen, J. R., Lin, L. D., and Machamer, C. E. (2011) Identification of a Golgi complextargeting signal in the cytoplasmic tail of the severe acute respiratory syndrome coronavirus envelope protein. J. Virol. 85, 5794-5803

27. Lim, K. P., and Liu, D. X. (2001) The missing link in coronavirus assembly. Retention of the avian coronavirus infectious bronchitis virus envelope protein in the pre-Golgi compartments and physical interaction between the envelope and membrane proteins. J. Biol. Chem. 276, 17515-17523

28. To, J., Surya, W., Fung, T. S., Li, Y., Verdia-Baguena, C., Queralt-Martin, M., Aguilella, V. M., Liu, D. X., and Torres, J. (2017) Channel-Inactivating Mutations and Their Revertant Mutants in the Envelope Protein of Infectious Bronchitis Virus. J. Virol. 91

29. Raamsman, M. J., Locker, J. K., de Hooge, A., de Vries, A. A., Griffiths, G., Vennema, H., and Rottier, P. J. (2000) Characterization of the coronavirus mouse hepatitis virus strain A59 small membrane protein E. J. Virol. 74, 2333-2342

30. Nagy, J. K., Kuhn Hoffmann, A., Keyes, M. H., Gray, D. N., Oxenoid, K., and Sanders, C. R. (2001) Use of amphipathic polymers to deliver a membrane protein to lipid bilayers. FEBS Lett. 501, 115-120

31. Gorzelle, B. M., Hoffman, A. K., Keyes, M. H., Gray, D. N., Ray, D. G., and Sanders, C. R. (2002) Amphipols can support the activity of a membrane enzyme. J. Am. Chem. Soc. 124, 11594-11595

32. Tribet, C., Audebert, R., and Popot, J. L. (1996) Amphipols: polymers that keep membrane proteins soluble in aqueous solutions. Proc. Natl. Acad. Sci. U S A 93, 15047-15050

33. Popot, J.-L. (2018) Membrane Proteins in Aqueous Solutions : From Detergents to Amphipols. in Biological and Medical Physics, Biomedical Engineering, , 1st Ed., Springer International Publishing : Imprint: Springer, Cham

34. Fernandez, A., Le Bon, C., Baumlin, N., Giusti, F., Cremel, G., Popot, J. L., and Bagnard, D. (2014) In vivo characterization of the biodistribution profile of amphipol A835. J. Membr. Biol. 247, 1043-1051

35. Tifrea, D. F., Pal, S., le Bon, C., Cocco, M. J., Zoonens, M., and de la Maza, L. M. (2020) Improved protection against Chlamydia muridarum using the native major outer membrane protein trapped in Resiquimod-carrying amphipols and effects in protection 
with addition of a Th1 (CpG-1826) and a Th2 (Montanide ISA 720) adjuvant. Vaccine 38, 4412-4422

36. Tifrea, D. F., Pal, S., Le Bon, C., Giusti, F., Popot, J. L., Cocco, M. J., Zoonens, M., and de la Maza, L. M. (2018) Co-delivery of amphipol-conjugated adjuvant with antigen, and adjuvant combinations, enhance immune protection elicited by a membrane proteinbased vaccine against a mucosal challenge with Chlamydia. Vaccine 36, 6640-6649

37. Popot, J. L., Berry, E. A., Charvolin, D., Creuzenet, C., Ebel, C., Engelman, D. M., Flotenmeyer, M., Giusti, F., Gohon, Y., Hong, Q., Lakey, J. H., Leonard, K., Shuman, H. A., Timmins, P., Warschawski, D. E., Zito, F., Zoonens, M., Pucci, B., and Tribet, C. (2003) Amphipols: polymeric surfactants for membrane biology research. Cell Mol. Life Sci. 60, 1559-1574

38. Wilson, L., McKinlay, C., Gage, P., and Ewart, G. (2004) SARS coronavirus E protein forms cation-selective ion channels. Virology 330, 322-331

39. Xia, B., Shen, X., He, Y., Pan, X., Wang, Y., Yang, F., Fang, S., Wu, Y., Zuo, X., Xie, Z., Jiang, X., Chi, H., Meng, Q., Zhou, H., Zhou, Y., Cheng, X., Chen, T., Xin, X., Jiang, H., Xiao, G., Zhao, Q., Zhang, L.-K., Shen, J., Li, J., and Gao, Z. (2020) SARS-CoV-2 envelope protein causes acute respiratory distress syndrome (ARDS)-like pathological damage and constitutes an antiviral target. bioRxiv, 2020.2006.2027.174953

40. Pocanschi, C. L., Dahmane, T., Gohon, Y., Rappaport, F., Apell, H. J., Kleinschmidt, J. H., and Popot, J. L. (2006) Amphipathic polymers: tools to fold integral membrane proteins to their active form. Biochemistry 45, 13954-13961

41. Valyaeva, A. A., Zharikova, A. A., Kasianov, A. S., Vassetzky, Y. S., and Sheval, E. V. (2020) Expression of SARS-CoV-2 entry factors in lung epithelial stem cells and its potential implications for COVID-19. Sci. Rep. 10, 17772

42. An, S., Chen, C. J., Yu, X., Leibowitz, J. L., and Makino, S. (1999) Induction of apoptosis in murine coronavirus-infected cultured cells and demonstration of $E$ protein as an apoptosis inducer. J. Virol. 73, 7853-7859

43. Yang, Y., Xiong, Z., Zhang, S., Yan, Y., Nguyen, J., Ng, B., Lu, H., Brendese, J., Yang, F., Wang, H., and Yang, X. F. (2005) Bcl-xL inhibits T-cell apoptosis induced by expression of SARS coronavirus $\mathrm{E}$ protein in the absence of growth factors. Biochem. J. 392, 135-143

44. DeDiego, M. L., Nieto-Torres, J. L., Jimenez-Guardeno, J. M., Regla-Nava, J. A., Alvarez, E., Oliveros, J. C., Zhao, J., Fett, C., Perlman, S., and Enjuanes, L. (2011) Severe acute respiratory syndrome coronavirus envelope protein regulates cell stress response and apoptosis. PLoS Pathog. 7, e1002315

45. Johnston, J. A., Ward, C. L., and Kopito, R. R. (1998) Aggresomes: a cellular response to misfolded proteins. J. Cell Biol. 143, 1883-1898

46. Wileman, T. (2006) Aggresomes and autophagy generate sites for virus replication. Science 312, 875-878

47. Prentice, E., Jerome, W. G., Yoshimori, T., Mizushima, N., and Denison, M. R. (2004) Coronavirus replication complex formation utilizes components of cellular autophagy. $\mathrm{J}$. Biol. Chem. 279, 10136-10141

48. Maier, H. J., and Britton, P. (2012) Involvement of autophagy in coronavirus replication. Viruses 4, 3440-3451 
Figures

Figure 1

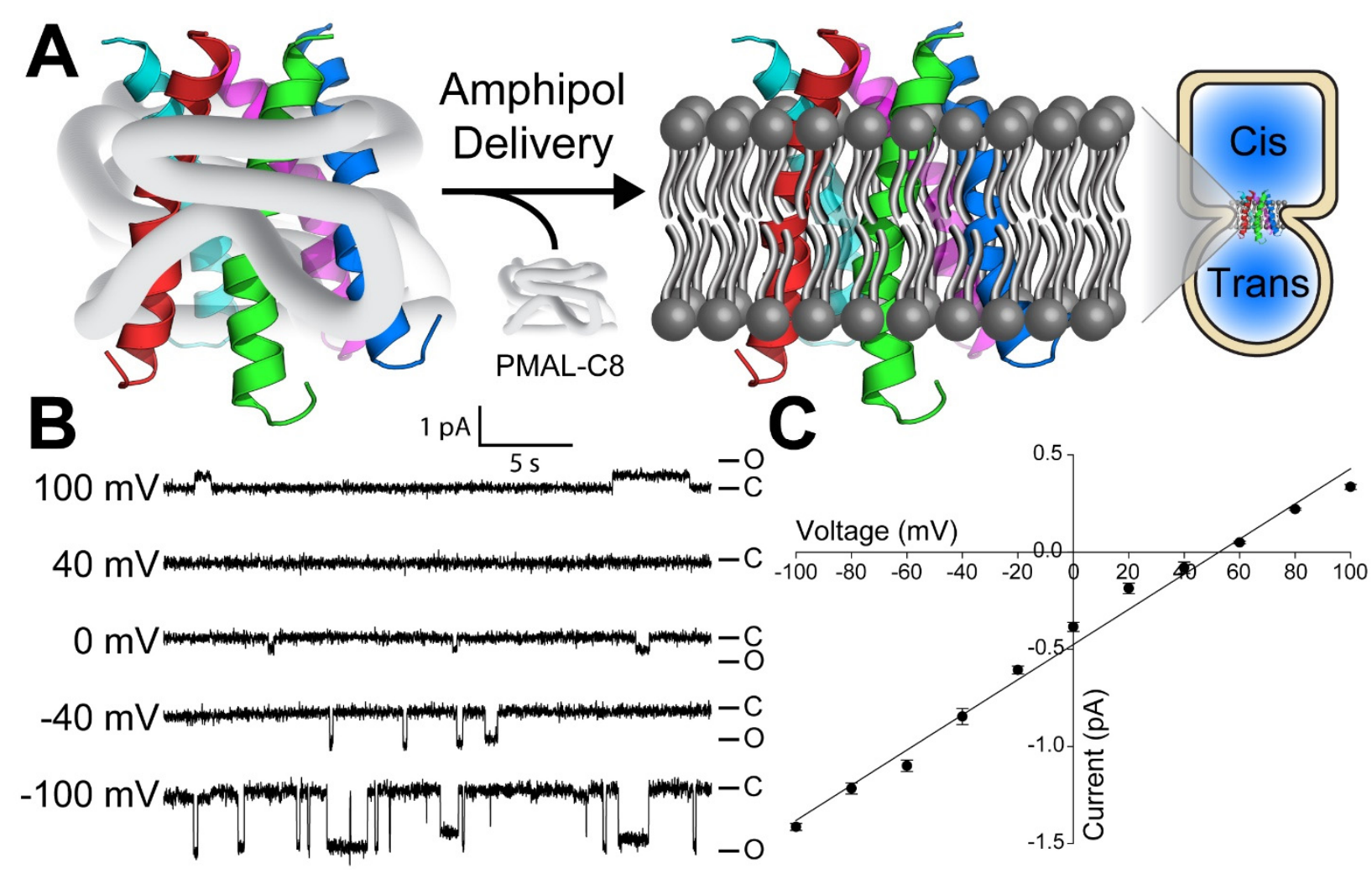

Figure 1. Functional delivery of SARS-CoV-2 envelope protein from amphipol complexes to planar lipid bilayers. (A) Schematic of SARS-CoV-2 envelope protein (S2-E) delivered using amphipols for membrane protein insertion into planar lipid bilayers. (B) Representative single-channel current recordings of PMAL-C8 amphipol-delivered S2-E as a function of transmembrane electrical potential show ion channel activity in POPC:POPE (3:1) planar bilayers, where S2-E fluctuates between closed $(C)$ and open $(O)$ states. (C) The S2-E currentvoltage relationship identifies a conductance of $9.0 \pm 0.3 \mathrm{pS}$ and a reversal potential of $53 \pm 3$ $\mathrm{mV}$ in an asymmetric $\mathrm{NaCl}$ buffer, indicative of cation selectivity. Data represent three replicates. Error bars are SEM from the three distinct amphipol delivery experiments on different days. 

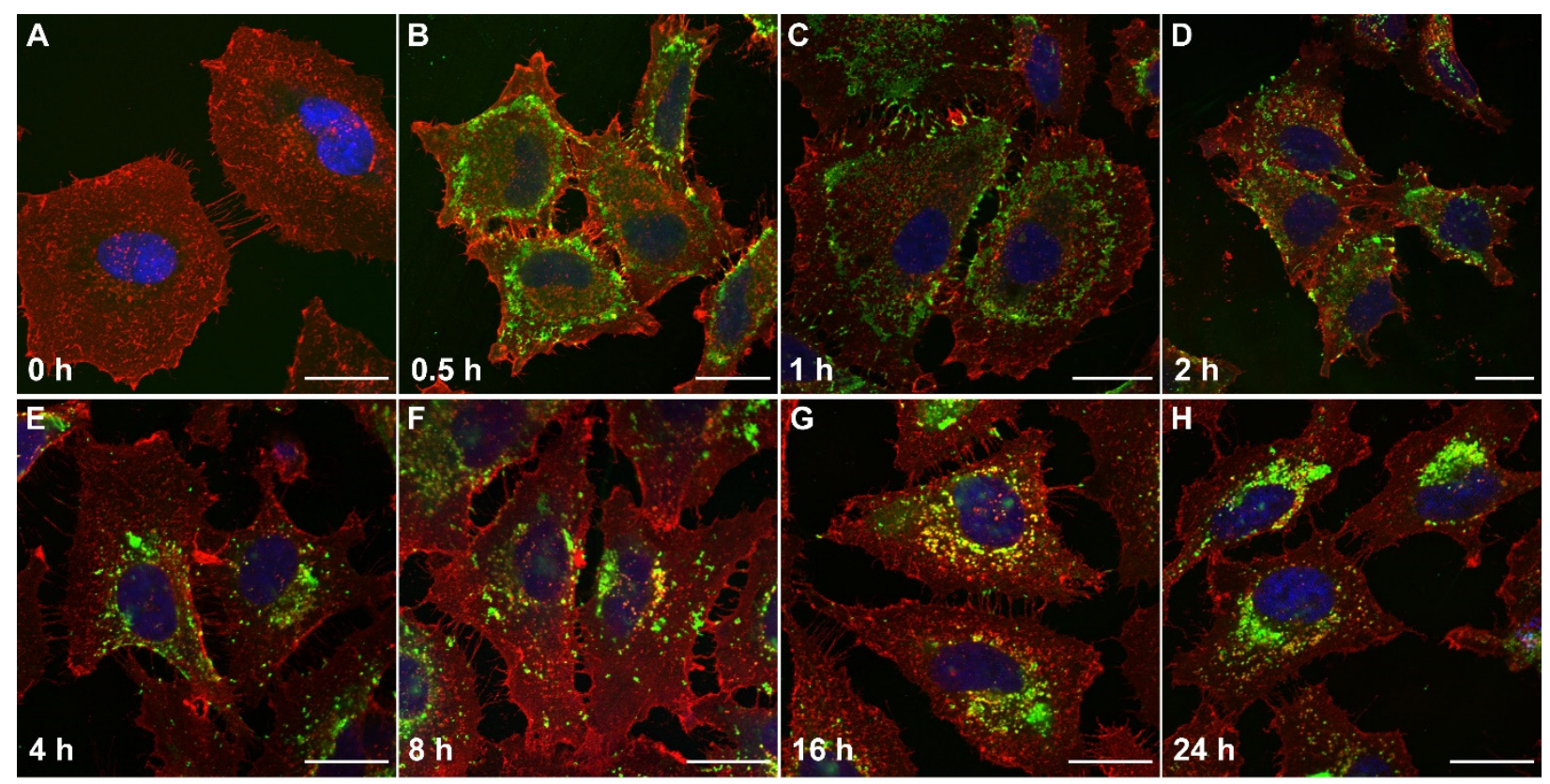

S2-E-NBD Cell surface Nucleus

Figure 2. Uptake of amphipol delivered SARS CoV-2 E protein by cells and subsequent intracellular trafficking of the protein. Representative confocal microscopy images of HeLa cells at various time points following treatment with amphipol-complexed $2.5 \mu \mathrm{M} S 2-\mathrm{E}$ labeled with NBD (S2-E-NBD). Color markers are: green, S2-E-NBD; red, cell membrane (WGAAF555); blue, cell nucleus (DRAQ5). (A) is the untreated $(0 \mu \mathrm{M})$ sample and $0 \mathrm{~h}$ time point, (B) is cells $0.5 \mathrm{~h}$ after treatment, (C) is following $1 \mathrm{~h},(\mathbf{D}) 2 \mathrm{~h},(\mathbf{E}) 4 \mathrm{~h},(\mathbf{F}) 8 \mathrm{~h},(\mathbf{G}) 16 \mathrm{~h}$, and (H) $24 \mathrm{~h}$. The S2-E-NBD signal migrates from the cell plasma membrane (see panel B), towards the perinuclear space (see panels $\mathrm{G}$ and $\mathrm{H}$ ). Time course experiments, using the same cell markers were independently repeated 3 times using 3 different S2-E-NBD preparations. All scale bars are $25 \mu \mathrm{m}$. See further details in the Supporting Information Materials and Methods and Fig. S5. 

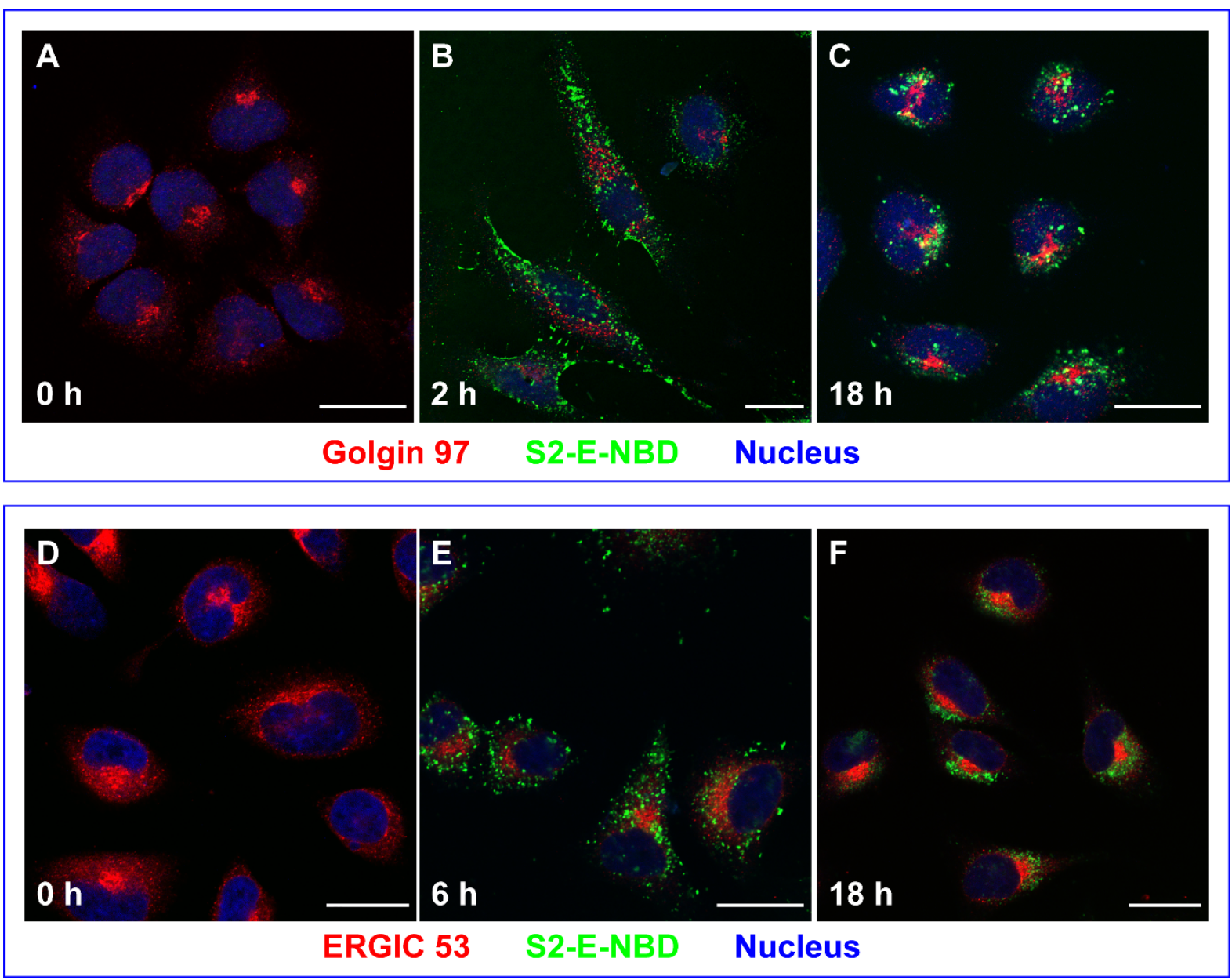

Figure 3. SARS-CoV-2 envelope protein traffics to a perinuclear location and accumulates near the Golgi and ERGIC compartments. Representative confocal microscopy images showing HeLa cells treated with $2.5 \mu \mathrm{M}$ S2-E-NBD. Color markers are: green, S2-E labeled with NBD; red-in panels A-C—is from an antibody to Golgin-97, a Golgi marker; in panels D-F, red is from an antibody to ERGIC-53, a defining marker for the ERGIC region; blue is the fluorescent dye DRAQ5, marking the cell nucleus. Panels (A) and (D) are the control samples where cells were not treated with S2-E-NBD. Other panels are labeled with time following S2-E-NBD addition to the cell culture. Experiments were repeated 3 times using 3 different S2-E-NBD preparations. All scale bars are $25 \mu \mathrm{m}$. Further details in materials and methods and Supporting Information Fig. $\mathbf{S 6}$ 